\title{
Epiaortic scanning for myocardial surgical revascularization
}

\author{
Alistair Royse $^{1,2}$, Johan Heiberg ${ }^{3}$, Colin Royse $e^{1,4,5}$ \\ 'Department of Surgery, University of Melbourne, Melbourne, Victoria 3052, Australia. \\ ${ }^{2}$ Department of Cardiothoracic Surgery, Royal Melbourne Hospital, Parkville, Victoria 3050, Australia. \\ ${ }^{3}$ Department of Anesthesiology, Centre of Head and Orthopaedics, Copenhagen University Hospital, Cophenhagen 2100, \\ Denmark. \\ ${ }^{4}$ Department of Anaesthesia and Pain Management, Royal Melbourne Hospital, Parkville, Victoria 3050, Australia. \\ ${ }^{5}$ Outcomes Research Consortium, Cleveland Clinic, Cleveland, Ohio, OH 44195, USA.
}

Correspondence to: Prof. Alistair Royse MD, Department of Surgery, University of Melbourne, 300 Grattan StCarlton, Melbourne, Victoria 3050, Australia. E-mail: alistair.royse@unimelb.edu.au

How to cite this article: Royse A, Heiberg J, Royse C. Epiaortic scanning for myocardial surgical revascularization. Vessel Plus 2021;5:23. https://dx.doi.org/10.20517/2574-1209.2020.95

Received: 18 Dec 2020 First Decision: 13 Jan 2021 Revised: 13 Jan 2021 Accepted: 22 Feb 2021 Published: 13 May 2021

Academic Editor: Cristiano Spadaccio Copy Editor: Xi-Jun Chen Production Editor: Xi-Jun Chen

\begin{abstract}
Coronary artery bypass grafting may involve substantial manipulation of the ascending aorta, including aortic cannulation, antegrade cardioplegia line cannulation, and aortic clamping. These distortions of the ascending aorta can lead to disruption of soft or calcified plaques in the aortic wall, which can cause embolization. A relationship has been shown between the degree of aortic manipulation and the degree of cerebral embolization. Thus, it is clear that the risk of cerebral embolization can be reduced by alterations in the surgical technique. Such surgical alterations can be guided by epiaortic ultrasound by assisting the surgeon in identifying regions where atherosclerosis is present to avoid or minimize the degree of aortic manipulation in these regions. By using a previously published examination protocol, the atherosclerotic regions can be found more efficiently with an ultrasound examination than manual palpation, and the entire examination can be completed within 3-5 min. This review aims to outline the current evidence to support the use of epiaortic ultrasound for myocardial surgical revascularization.
\end{abstract}

Keywords: Atherosclerosis, cardiac surgical procedures, epiaortic, ultrasound 


\section{INTRODUCTION}

Conventional coronary bypass surgery involves significant manipulation of the ascending aorta. At a minimum, the aortic cannulation, antegrade cardioplegia line cannulation, and aortic clamping are significant distortions of the ascending aorta, which could disrupt soft or calcified plaques in the wall of the aorta and embolize their contents ${ }^{[1-4]}$. However, it is also common that additional aortic manipulation occurs with the construction of proximal aortic anastomoses for coronary grafting. This may be particularly extensive when a partial occlusion clamp is used. The opposite strategy is the complete avoidance of any manipulation of the ascending aorta by using a composite graft from the attached left or right internal mammary for inflow and circumvention of cardiopulmonary bypass with its associated cannulation and clamping ${ }^{[5-10]}$.

From these 2 extremes, the cerebrovascular accident rate related to emboli to the brain can be taken as a surrogate for emboli to other parts of the body. Further, the relationship between the degree of aortic manipulation and the degree of cerebral embolization has been demonstrated clearly by several studies $^{[3,4,9,11-15]}$. The greater the degree of aortic manipulation, the greater the degree of cerebral embolization. Hence, it is clear that alterations in the surgical technique to avoid dislodgement of aortic atheroma can reduce the risk of cerebral embolization.

\section{WHAT IS THE ROLE OF ULTRASOUND OF THE AORTA?}

There is a common misunderstanding of the role of epiaortic ultrasound examination. The notion that ultrasound alone directly leads to reduced cerebral or other end-organ embolization is not valid. After all, it is merely a diagnostic test that can identify the presence of atherosclerosis. To reduce embolization, the ultrasound must guide the surgeon to alter their surgical technique for avoiding or minimizing the degree of aortic manipulation in the regions where atherosclerosis is present.

The precise locality of atherosclerosis in the aorta is crucial to avoiding the binary view that either aortic manipulation without ultrasound is not important or safe-or the polar opposite argument that no aortic manipulation is safe under any circumstances. The aorta can be manipulated safely provided that there is no aortic manipulation occurring at the site of aortic atherosclerosis. Specifically, in combination with the use of epiaortic ultrasound to precisely define the locality of aortic atherosclerosis, the aorta can be manipulated safely ${ }^{[16,17]}$.

Finally, it is important to realize that transesophageal echocardiography has a "blind spot" overlying the distal ascending aorta and proximal aortic arch, caused by the presence of air in the bronchus between the esophagus and the aorta preventing ultrasound transmission ${ }^{[1,19]}$.

These sites are for aortic cannulation and aortic clamping, and consequently, adequate imaging of these sites is crucial. Essentially, the ascending aorta and proximal aortic arch can only be fully interrogated with ultrasound by using a handheld ultrasound probe.

\section{ALTERATIONS IN THE SURGICAL TECHNIQUE}

Unless novel coronary revascularisation techniques can be employed by the surgeon when required, there is often little value to epiaortic ultrasound. This is simply because all of the available space on the ascending aorta is used during a conventional aorta to coronary bypass graft operation. Consider the grafting orientation during conventional surgery: 
- The proximal ascending aorta close to the sinotubular junction and the Sinuses of Valsalva are not available for proximal aortic anastomoses as the angle of the graft arising from the aorta is too acute and would lead to kinking of the graft. Therefore, these proximal anastomoses are generally applied to the midportion of the ascending aorta.

- The aortic cannulation site is usually the distal ascending aorta or proximal aortic arch. Therefore, the aortic clamp is immediately adjacent, compressing the distal ascending aorta, and the antegrade cardioplegia catheter is therefore immediately proximal to the clamp.

For these various purposes, the entire ascending aorta is "allocated", which means that if epiaortic ultrasound were to detect atherosclerosis, which could affect any of these sites, and then to avoid atherosclerosis, some alteration to the grafting or cannulation arrangement would be required. However, in that case, there is no option to significantly alter the position of any of the grafts, cannulation, or clamps, and the knowledge of aortic atherosclerosis being present is of little value.

Specifically, if there was atherosclerosis present at the site of the intended aortic cannulation, then logically, the surgeon should move that point of manipulation to a more proximal (or theoretically more distal) site. Alternatively, if the aortic cannulation site is satisfactory, but there was a large plaque present at the intended clamping site, the aortic clamp should be moved more proximally to an area free of atherosclerosis, and additionally, the antegrade cardioplegia catheter should also be moved more proximally to the clamp. This would not be possible if this segment of the ascending aorta was otherwise allocated for the construction of proximal aortic anastomoses but would only be possible if there were no aortic anastomoses. Thus, it would be possible only if a composite grafting technique was employed so that there were no proximal aortic anastomoses.

It follows that for the full benefit of epiaortic ultrasound of the aorta to be realized, flexibility of the technique employed by the surgeon is essential, even if the technique is only occasionally used. However, most surgeons are uncomfortable with techniques that they do not usually or otherwise routinely employ.

\section{THE SURGEON'S FINGER VERSUS THE ULTRASOUND PROBE}

Although the time needed to learn the technique, interpret the images, and conduct an epiaortic ultrasound examination is small, there is considerable reluctance to do so, which is perplexing ${ }^{[20]}$. One common view is that the surgeon's "finger" is a very accurate assessment of aortic pathology, which, however, is far from true.

In general, imaging-based technologies are substantially superior to any form of manual palpation assessment in any form of medicine. Calcified aortic wall lesions offer more resistance to the finger's pressure, which means that the aortic wall is less likely to be deformable by pressure exerted on it, leading to easier detection by the finger. Nevertheless, the lesions that are most likely to break off and embolize are those that are soft, have ruptured surface elements, or contain soft lipid-rich elements. The latter are particularly susceptible to dislodgement by aortic manipulation. These soft elements are almost impossible to detect with the finger when pressure is applied to the sidewall of the aorta as they offer no counterresistance to the pressure. Therefore, the absence of counter-pressure would be interpreted by the surgeon as being "safe", yet this may reflect the opposite, a greater likelihood of embolization. Several studies have been performed comparing the efficacy of manual examination and ultrasound examination. Our group previously showed that manual palpation was only able to detect $50 \%$ of important atheroma compared with epiaortic ultrasound ${ }^{[20]}$. Similarly, Sylivris et al. ${ }^{[21]}$ found manual palpation to be very insensitive, 
detecting only 2 out of 36 segments of important atheroma in the ascending aorta. Both studies also indicated that transesophageal echocardiography was even less sensitive than manual palpation. Despite this, transesophageal echocardiography has been recommended as a screening tool for atheroma detection ${ }^{[22,23]}$. Importantly, however, the frequency of adequate imaging of the aortic zones 5-6 (distal aortic arch and descending aorta), Figure 1, is generally higher with transesophageal echocardiography than with epiaortic ultrasound. Still, as previously shown, a transesophageal echocardiographic inspection of zones 5 and 6 has a very high negative predictive value for atheroma in zones 1-4 (ascending aorta and proximal aortic arch). In contrast, it has a very low positive predictive value ${ }^{[2,23]}$. Atheroma is more frequent in older patient $^{[24]}$, which suggests that epiaortic ultrasound is of greater importance in older patients with moderate/severe atheroma in zones 5 and 6 . In contrast, its yield may be low in young patients with only nil/mild atheroma detected in these zones by transesophageal echocardiography. Thus transesophageal echocardiography and epiaortic ultrasound should be used as tools to complement each other rather than as alternatives.

\section{BARRIERS TO THE ADOPTION OF ROUTINE EPIAORTIC ULTRASOUND}

The belief that manual palpation is more accurate.

Lack of familiarity with the use of ultrasound technologies and concern about not being "trained" in its use.

Institutional or unit protocols, inter specialty conflicts, or personal psychological factors are generally prominent causes preventing surgeons from adopting these new technologies.

A disregard of the literature demonstrating a causal link between aortic manipulation and systemic or cerebral embolization.

Personal fear of not being considered to be the "expert" in the operating room.

Personal reluctance to consider alternative revascularization techniques that are not part of the surgeon's routine practice, such as reliance on composite grafting, sequential grafting, or use of multiple arterial grafting techniques.

Lack of ultrasound equipment.

\section{TRAINING}

Intraoperative transesophageal echocardiography is routine in many parts of the Western world. Therefore, there is a good level of basic ultrasound experience and knowledge amongst cardiac surgeons from the general observation of ultrasound being performed. With this familiarity, the performance of epiaortic ultrasound examination is extremely simple to implement. For others, however, learning epiaortic ultrasound may be considered as difficult even though this examination is quite straightforward and simple to perform. Similarly, interpreting the images is very simple since the precise locality of an atheroma is very easy to appreciate, and it is always directly beneath the ultrasound probe at the time. In our personal experience, a surgical trainee with previous practical and theoretical experience in ultrasound or echocardiography often only needs 5-10 cases to be able to competently and confidently perform an epiaortic ultrasound examination. Lastly, learning epiaortic ultrasound examination may be a sufficient enough stimulus to engage in wider use of ultrasound technologies such as transthoracic echocardiography in the pre-and postoperative settings, ultrasound guided procedures including pleural drainage and 


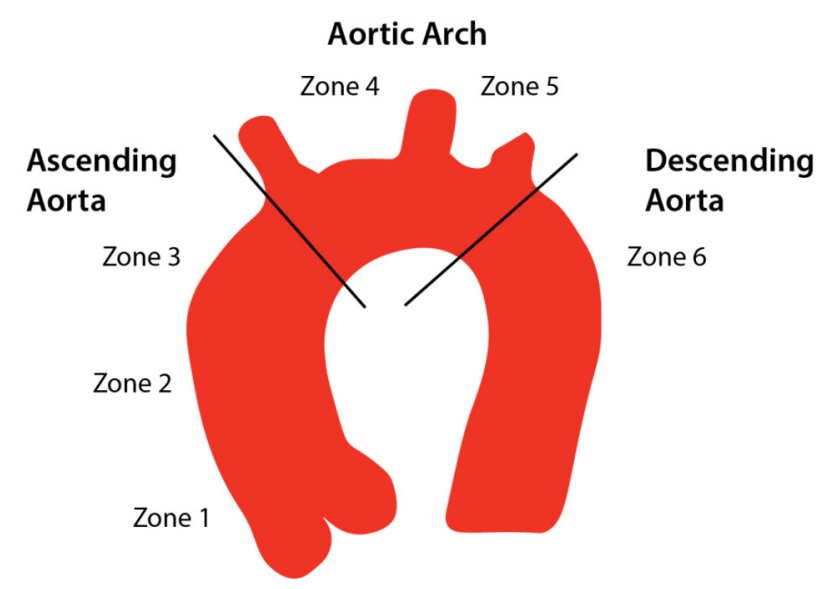

Figure 1. Ultrasound examination zones for the thoracic aorta. The ascending aorta is divided into proximal, mid and distal (zones 1-3), the arch into proximal and distal (zones 4-5) and descending (zone 6); after Royse et al. ${ }^{[25-27]}$.

ultrasound lung examinations.

\section{THE SCANNING PROTOCOL}

We have published a comprehensive examination protocol ${ }^{[26,27]}$ with guidelines from the American Society of Echocardiography and the Society of Cardiovascular Anesthesiologists ${ }^{[28]}$. It is recommended that both the proximal left main and right coronary arteries are included in a routine fashion, as well as the aortic arch. Additionally, these same techniques can be used in an ad hoc manner in an identical fashion. For example, following an aortic valve replacement, the same technique for imaging of the right coronary artery prior to cannulation can be used to assess flow in the native right coronary artery if there is concern about partial or complete obstruction of the origin of the right mid coronary artery. This obviates entirely the "reflex grafting" of the right coronary artery in case of right ventricular dysfunction early after removing the aortic clamp

\section{THE ULTRASOUND PROBE}

The examination is conducted on a superficial structure, generally, less than $5 \mathrm{~cm}$ in diameter, and therefore the higher the frequency of the probe, the better the resolution will be. Additionally, the probe needs to be used within a sterile field. Ideally, the probe itself is sterilized, but generally, use of the probe within a sterile plastic barrier sheath is undertaken. Either works well, provided there is a good acoustic couple between the tissue and the probe, which requires the use of sterile acoustic gel.

\section{RECOMMENDED SCANNING SEQUENCE}

The recommended sequence of interrogation, Figure 2 is firstly to image the aortic valve in the long axis, which overlies the origin of the right coronary artery. Then the probe can be rotated $90^{\circ}$ to follow the right coronary artery in short axis, along the atrioventricular groove as far as the acute margin of the heart. Then the probe can be orientated in a sagittal plane between the aorta and the pulmonary artery to image the left main coronary artery as well as the proximal left descending and circumflex artery. The probe is then rotated $90^{\circ}$ to the ascending aorta, and the proximal, mid, and distal ascending parts of the aorta are imaged, ensuring that the probe is at $90^{\circ}$ to the aorta at each site. If the aorta is enlarged, the probe is moved accordingly to image all of the aorta and can be used to image the aorta in the long axis, if required. Lastly, the probe is rotated $45^{\circ}$ to image the aortic arch in the long axis, and by angling superiorly, the cerebral vessels can be imaged as well. The same technique can be used for a number of other alternative ad hoc 

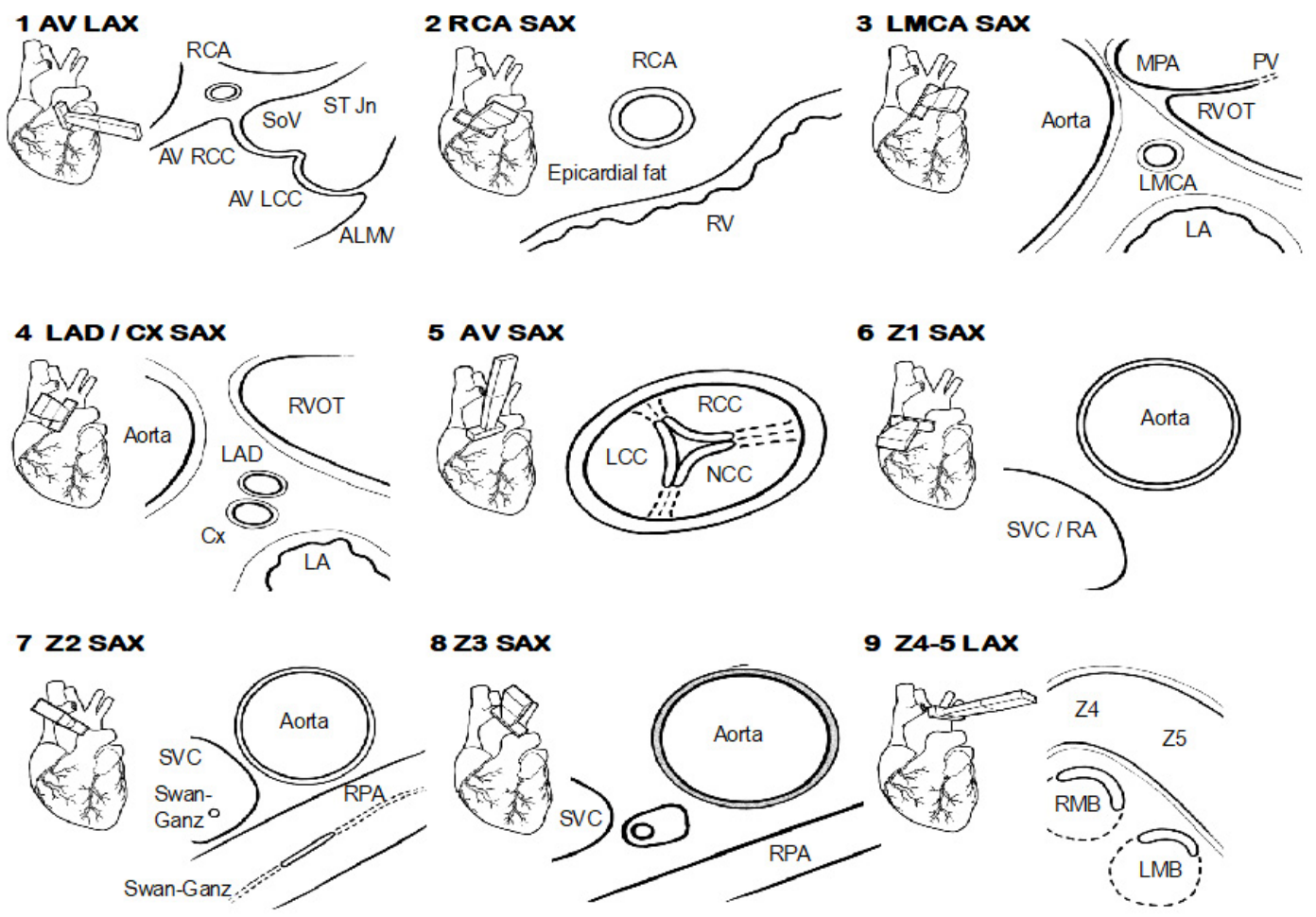

8 Z3 SAX

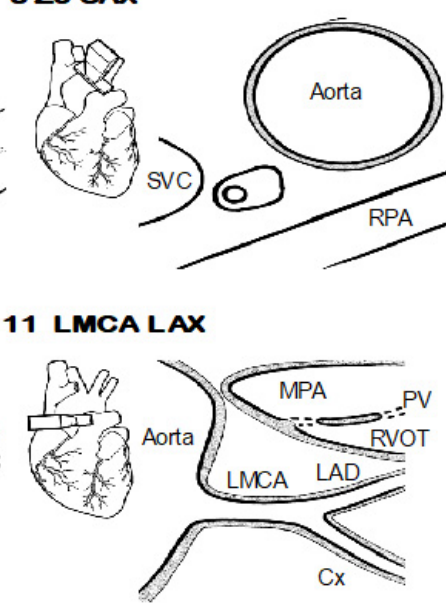

9 Z4-5 LAX
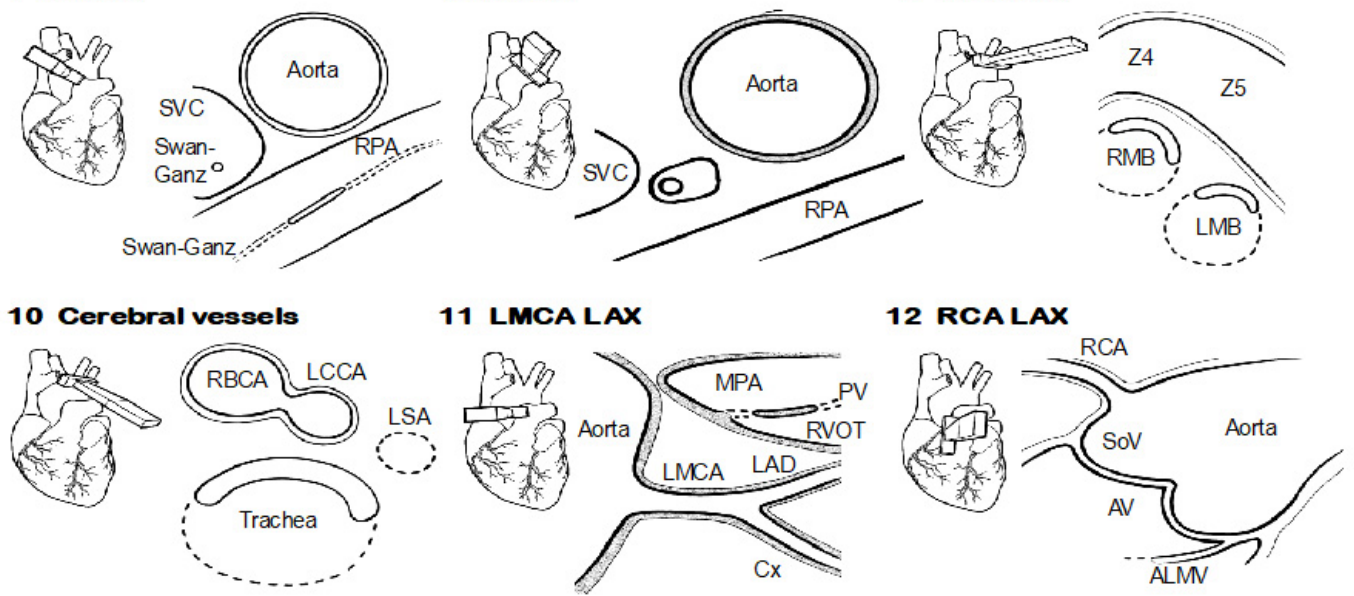

Figure 2. A standardized intraoperative ultrasound examination of the thoracic aorta and proximal coronary arteries. Reproduced with permission ${ }^{[27]}$. LAX: Longitudinal axis; SAX: short axis; RCA: right coronary artery; SoV: Sinus of Valsalva; AV: aortic valve; RCC: right coronary cusp of aortic valve; LCC: left coronary cusp; NCC: non coronary cusp; ST In: sinotubular junction of aorta; ALMV: anterior leaflet of mitral valve; RV: right ventricle; RVOT: right ventricular outflow tract; MPA: main pulmonary artery; PV: pulmonary valve; LA: left atrium; LAD: left anterior descending artery; Cx: circumflex coronary artery; SVC: superior vena cava; RA: right atrium; RPA: right pulmonary artery; Z1: zone 1 or proximal ascending aorta; Z2: zone 2 or mid ascending; Z3: zone 3 or distal ascending; Z4: zone 4 or proximal aortic arch; Z5: zone 5 or distal aortic arch; RMB: right main bronchus; LMB: left main bronchus; RBCA: right brachiocephalic artery; LCCA: left common carotid artery; LSA: left subclavian artery; LMCA: left main coronary artery. Copyright 2006, with permission from the European Association for Cardio-thoracic Surgery.

uses, such as imaging grafts, anastomoses, and other structures such as the interatrial septum. Generally, in the hands of an expert, the entire examination is completed within 3-5 min, and thus, there is no meaningful delay in the conduct of the surgery.

\section{CONCLUSIONS AND FUTURE DIRECTIONS}

Epiaortic ultrasound is superior to manual palpation in the assessment of aortic atheroma, which may reduce the risk of plaque embolization substantially during conventional coronary artery bypass grafting. Generally, the performance of epiaortic ultrasound examination is simple, and an examination can be completed within a few minutes. Even though several studies have reported higher efficacies of epiaortic ultrasound compared with manual palpation and transesophageal echocardiography, trials remain warranted to compare the risk of systemic or cerebral embolization and clinical outcomes. 


\section{DECLARATIONS}

\section{Authors' contributions}

Made substantial contributions to conception and design of the commentary and performed data interpretation: Royse A, Heiberg J, Royse C

\section{Availability of data and materials}

Not applicable.

\section{Financial support and sponsorship}

None.

\section{Conflicts of interest}

All authors declared that there are no conflicts of interest.

\section{Ethical approval and consent to participate}

Not applicable.

\section{Consent for publication}

Not applicable.

\section{Copyright}

(c) The Author(s) 2021.

\section{REFERENCES}

1. Calafiore AM, Di Mauro M, Teodori G, et al. Impact of aortic manipulation on incidence of cerebrovascular accidents after surgical myocardial revascularization. Ann Thorac Surg 2002;73:1387-93. DOI PubMed

2. Douglas JM, Spaniol SE. A multimodal approach to the prevention of postoperative stroke in patients undergoing coronary artery bypass surgery. Am J Surg 2009;197:587-90. DOI PubMed

3. Shroyer AL, Coombs LP, Peterson ED, et al. The Society of Thoracic Surgeons: 30-day operative mortality and morbidity risk models. Ann Thorac Surg 2003;75:1856-64. DOI PubMed

4. Mahanna EP, Blumenthal JA, Blumenthal JA, et al. Defining neuropsychological dysfunction after coronary artery bypass grafting. Ann Thorac Surg 1996;61:1342-7. DOI PubMed

5. Misfeld M, Potger K, Ross DE, et al. "Anaortic” off-pump coronary artery bypass grafting significantly reduces neurological complications compared to off-pump and conventional on-pump surgery with aortic manipulation. Thorac Cardiovasc Surg 2010;58:408-14. DOI PubMed

6. Ross DE. Anaortic coronary bypass surgery. Semin Thorac Cardiovasc Surg 2012;24:90-2. DOI PubMed

7. Vallely MP, Potger K, McMillan D, et al. Anaortic techniques reduce neurological morbidity after off-pump coronary artery bypass surgery. Heart Lung Circ 2008;17:299-304. DOI PubMed

8. Vallely MP, Yan TD, Edelman JJ, Hayman M, Brereton RJ, Ross DE. Anaortic, total-arterial, off-pump coronary artery bypass surgery: how to do it. Heart Lung Circ 2010;19:555-60. DOI PubMed

9. Royse AG, Royse CF, Royse CF, et al. Reduced neuropsychological dysfunction using epiaortic echocardiography and the exclusive Y graft. Ann Thorac Surg 2000;69:1431-8. DOI PubMed

10. Royse AG, Royse CF, Raman JS. Exclusive Y graft operation for multivessel coronary revascularization. Ann Thorac Surg 1999;68:1612-8. DOI PubMed

11. Barbut D, Gold JP. Aortic atheromatosis and risks of cerebral embolization. J Cardiothorac Vasc Anesth 1996;10:24-30. DOI PubMed

12. Djaiani G, Fedorko L, Borger M, et al. Mild to moderate atheromatous disease of the thoracic aorta and new ischemic brain lesions after conventional coronary artery bypass graft surgery. Stroke 2004;35:e356-8. DOI PubMed

13. Vanninen R, Aikiä M, Könönen M, et al. Subclinical cerebral complications after coronary artery bypass grafting: prospective analysis with magnetic resonance imaging, quantitative electroencephalography, and neuropsychological assessment. Arch Neurol 1998;55:618-27. DOI PubMed

14. Zamvar V, Williams D, Hall J, et al. Assessment of neurocognitive impairment after off-pump and on-pump techniques for coronary artery bypass graft surgery: prospective randomised controlled trial. BMJ 2002;325:1268. DOI PubMed PMC

15. Royse AG, Royse CF. Epiaortic ultrasound, Y graft, and postoperative neuropsychological dysfunction - Reply. Ann Thorac Surg 2001;71:398. DOI

16. Rosenberger P, Shernan SK, Löffler M, et al. The influence of epiaortic ultrasonography on intraoperative surgical management in 
6051 cardiac surgical patients. Ann Thorac Surg 2008;85:548-53. DOI PubMed

17. Whitley WS, Glas KE. An argument for routine ultrasound screening of the thoracic aorta in the cardiac surgery population. Semin Cardiothorac Vasc Anesth 2008;12:290-7. DOI PubMed

18. Zaane B, Zuithoff NP, Reitsma JB, Bax L, Nierich AP, Moons KG. Meta-analysis of the diagnostic accuracy of transesophageal echocardiography for assessment of atherosclerosis in the ascending aorta in patients undergoing cardiac surgery. Acta Anaesthesiol Scand 2008;52:1179-87. DOI PubMed

19. Yamaguchi A, Adachi H, Tanaka M, Ino T. Efficacy of intraoperative epiaortic ultrasound scanning for preventing stroke after coronary artery bypass surgery. Ann Thorac Cardiovasc Surg 2009;15:98-104. PubMed

20. Royse C, Royse A, Blake D, Grigg L. Screening the thoracic aorta for atheroma: a comparison of manual palpation, transesophageal and epiaortic ultrasonography. Ann Thorac Cardiovasc Surg 1998;4:347-50. PubMed

21. Sylivris S, Calafiore P, Matalanis G, et al. The intraoperative assessment of ascending aortic atheroma: Epiaortic imaging is superior to both transesophageal echocardiography and direct palpation. J Cardiothorac Vasc Anesth 1997;11:704-7. DOI PubMed

22. Hartman GS, Yao FS, Bruefach M 3rd, et al. Severity of aortic atheromatous disease diagnosed by transesophageal echocardiography predicts stroke and other outcomes associated with coronary artery surgery: a prospective study. Anesth Analg 1996;83:701-8. DOI PubMed

23. Konstadt SN, Reich DL, Kahn R, Viggiani RF. Transesophageal echocardiography can be used to screen for ascending aortic atherosclerosis. Anesth Analg 1995;81:225-8. DOI PubMed

24. Wareing TH, Davila-roman VG, Daily BB, et al. Strategy for the reduction of stroke incidence in cardiac surgical patients. Ann Thorac Surg 1993;55:1400-7. DOI PubMed

25. Royse C, Royse A, Blake D, Grigg L. Assessment of thoracic aortic atheroma by echocardiography: a new classification and estimation of risk of dislodging atheroma during three surgical techniques. Ann Thorac Cardiovasc Surg 1998;4:72-7. PubMed

26. Royse AG, Royse CF. Epiaortic ultrasound assessment of the aorta in cardiac surgery. Best Pract Res Clin Anaesthesiol 2009;23:33541. DOI PubMed

27. Royse A, Royse C. A standardised intraoperative ultrasound examination of the aorta and proximal coronary arteries. Interact Cardiovasc Thorac Surg 2006;5:701-4. DOI PubMed

28. Glas KE, Swaminathan M, Reeves ST, et al; Council for Intraoperative Echocardiography of the American Society of Echocardiography; Society of Cardiovascular Anesthesiologists; Society of Thoracic Surgeons. Guidelines for the performance of a comprehensive intraoperative epiaortic ultrasonographic examination: recommendations of the American Society of Echocardiography and the Society of Cardiovascular Anesthesiologists; endorsed by the Society of Thoracic Surgeons. Anesth Analg 2008;106:1376-84. DOI PubMed 